LAWRENCE LIVERMORE N A T IO N A L LABORATORY
Pre-experiment testing of the Multi Channel Systems 16-channel preamplifier CPA16

J. B. Patin, M. A. Stoyer, K. J. Moody, A. V.

Friensehner

November 18, 2003 
This document was prepared as an account of work sponsored by an agency of the United States Government. Neither the United States Government nor the University of California nor any of their employees, makes any warranty, express or implied, or assumes any legal liability or responsibility for the accuracy, completeness, or usefulness of any information, apparatus, product, or process disclosed, or represents that its use would not infringe privately owned rights. Reference herein to any specific commercial product, process, or service by trade name, trademark, manufacturer, or otherwise, does not necessarily constitute or imply its endorsement, recommendation, or favoring by the United States Government or the University of California. The views and opinions of authors expressed herein do not necessarily state or reflect those of the United States Government or the University of California, and shall not be used for advertising or product endorsement purposes.

This work was performed under the auspices of the U.S. Department of Energy by University of California, Lawrence Livermore National Laboratory under Contract W-7405-Eng-48. 
UCRL-TR-201021

Pre-experiment testing of the Multi Channel Systems 16-channel preamplifier CPA16

J. B. Patin, M. A. Stoyer, K. J. Moody, and A. V. Friensehner

University of California, Lawrence Livermore National Laboratory, Livermore, CA 94551 


\title{
Pre-experiment testing of the Multi Channel Systems 16-channel preamplifier CPA16
}

\author{
J. B. Patin, M. A. Stoyer, K. J. Moody, and A. V. Friensehner \\ University of California, Lawrence Livermore National Laboratory, Livermore, CA 94551
}

The 16-channel preamplifier model CPA16 from Multi Channel Systems was studied. The CPA16 preamplifier/amplifier module is a candidate to be used as the preamplifiers and amplifiers for the focal plane detectors of the Mass Analyzer of Super Heavy Atoms (MASHA). The equipment used to test the CPA16, the results of testing the CPA16 with a pulser, a mixed ${ }^{229} \mathrm{Th} /{ }^{148} \mathrm{Gd}$ source and a ${ }^{252} \mathrm{Cf}$ source, and a summary of the results will be presented.

\section{INTRODUCTION}

The MASHA [1] apparatus is currently being built in Dubna, Russia at FLNR, JINR as the next generation detector used by the Dubna/Livermore collaboration [2-6] for the detection of isotopes of the superheavy elements $(\mathrm{Z} \geq 114)$. MASHA will be used to identify the evaporation residues produced in the reaction of ${ }^{48} \mathrm{Ca}$ ions and heavy actinide targets $\left({ }^{238} \mathrm{U} \&{ }^{244} \mathrm{Pu}\right)$ by mass. Once operational, MASHA will allow the mass identification of superheavy nuclei with a resolution of approximately $0.25 \mathrm{amu}$. The excellent mass resolution will help positively identify the atomic mass of the previously observed isotopes of elements 112 and $114[2-3,6]$.

\section{EQUIPMENT}

Two Canberra PIPS detectors, model number SPD-25-10-100-AM detected alpha decay and spontaneous fission decay of the mixed ${ }^{229} \mathrm{Th} /{ }^{148} \mathrm{Gd}$ and ${ }^{252} \mathrm{Cf}$ sources. An Ortec Model 459 HV Power Supply supplied the $+60 \mathrm{~V}$ used by the PIPS detectors. A custom-made preamp power supply supplied the $\pm 6 \mathrm{~V}$ used by the preamplifier. This custom-made preamp power supply took the $\pm 6 \mathrm{~V}$ from the NIM bin and placed it on pin $5(+6 \mathrm{~V})$ and pin $8(-6 \mathrm{~V})$ of a 9pin SUB-D connector. A Berkeley Nucleonics Corporation Model 8010 Pulser supplied the pulser signals to the CPA16. A resistor and capacitor reduced the voltages of the signals from the pulser to the CPA16 to accurately model the voltage of a detector signal. Without the resistor and capacitor, the input voltages would be too high and would cause cross-talk across the 16-preamp/amp channels. Cross-talk is defined as unwanted leakage from one channel to another. The capacitance between two adjacent wires of the supplied ribbon cable was $15 \mathrm{pF}$. 
The measured capacitance between two alternate wires was $10 \mathrm{pF}$. The shortest possible ribbon cable between the detectors and the inputs of the CPA16 would be recommended to reduce possible cross-talk. An Ortec MCA card with a Windows PC running Ortec's Maestro software was used to obtain the spectra used to evaluate the CPA16. The input and output connections on the CPA16 were male 34 pin ribbon cable connections. The output of the single detector and the pulser and the input of the MCA card was a standard BNC connection. Therefore, a specially made LEMO to Ribbon Cable converter was created to connect the individual outputs/inputs of the detector, pulser and MCA card to the ribbon cable input/output of the CPA16. A schematic diagram of the electronics setup as described above is seen in Fig. 1.

\section{EVALUATION}

Initially, a signal from the pulser was observed at both before and after the CPA16 (Numbers 1, 2 and 3, Fig. 1). A trace of the output signal from the pulser is shown in Fig. 2 (Number 1, Fig. 1). The square wave pulser signal from Fig. 2 was fed into the CPA16 and the resulting oscilloscope output trace is shown in Fig. 3 (Number 2 and 3, Fig. 1).

Output oscilloscope traces like the ones seen in Fig. 3 were observed for all of the preamp/amp channels. To test for the likelihood of cross-talk between adjacent preamp/amp channels, the CPA16 was setup with the pulser output going into one preamp/amp channel, and the output signal was taken from the adjacent channel. For example, the pulser output was placed in the input of preamp/amp channel 16 and the output of preamp/amp channel 15 was recorded. No signals resulting from cross-talk were observed/detected after 24 hours, indicating that very little to no cross-talk is present between neighboring preamp/amp channels.

The amplitude of the pulser was increased to see how the CPA16 operated with increased input voltage. An oscilloscope was used to record the output voltages from the pulser and the output voltages from the preamp/amp. The output signal from the CPA16 saturated at $+5 \mathrm{~V}$ when the output signal of the pulser reached $-100 \mathrm{mV}$. 
After testing the CPA16 with a pulser, testing began with radioactive sources. Two different sources were used to test the response of the CPA16 to signals from a PIPS detector. One source was a mixed source comprised of ${ }^{229} \mathrm{Th}$ and ${ }^{148} \mathrm{Gd}$. The ${ }^{229} \mathrm{Th}$ decays by alpha- and beta-decay through ${ }^{225} \mathrm{Ac},{ }^{221} \mathrm{Fr}$, ${ }^{217}$ At, and ${ }^{213}$ Po ending at stable ${ }^{209} \mathrm{Bi}$. The ${ }^{148} \mathrm{Gd}$ decays to stable ${ }^{144} \mathrm{Sm}$. The mixed source was covered with $10 \mu \mathrm{g} / \mathrm{cm}^{2}$ of gold. The resulting alpha-decay energies and corrected energies can be found in Table 1. The oscilloscope trace of the low gain output (Number 2, Fig. 1) of the CPA16 to the mixed source is shown in Fig. 4.

The other source was a ${ }^{252} \mathrm{Cf}$ source used to analyze both the low and high gain amplification outputs. ${ }^{252} \mathrm{Cf}$ decays by both spontaneous fission decay and alpha decay, enabling the study of both the low and high gain channel outputs. The ${ }^{252} \mathrm{Cf}$ fission fragment energy distribution is centered at $78.3 \mathrm{MeV}$ and 103.5 MeV. The alpha-decay energy of ${ }^{252} \mathrm{Cf}$ is $6118.2 \mathrm{keV}$.

The study of the response of the CPA16 to signals from the PIPS detector began by looking at the mixed source located directly underneath the PIPS detector (approximately 0.125 in). Spectra were obtained during a 10-minute acquisition time. The resulting spectra were saved for peak value and resolution analysis. Two of the output ribbon cable to LEMO converter wirings were defective, and therefore no data was obtained for preamp/amp channel 2 and channel 14. These preamp/amp channels were tested without the ribbon cable to LEMO converters with the pulser and behaved similarly to the rest of the preamp/amp channels. A spectrum taken from one of the operational preamp/amp channels is shown in Fig. 5.

The Gaussian centroid for each alpha peak was obtained and a linear calibration was performed using the ${ }^{148} \mathrm{Gd},{ }^{221} \mathrm{Fr},{ }^{217} \mathrm{At}$, and ${ }^{213} \mathrm{Po}$ peaks. The ${ }^{229} \mathrm{Th}$ and ${ }^{225}$ Ac peaks were not used in the calibration, as there are multiple decay lines with similar energies from each isotope. Calibration slopes and intercepts as well as FWHM in keV for each peak for 14 of the 16-preamp/amp channels are located in Table 2.

The spectra from the 14 individual preamp/amp channels were summed to arrive at a composite spectrum for the 16-preamp/amp channels to examine the overall resolution for the detector and CPA16. The summed spectrum can be seen in Fig. 6 . 
The same procedure used for the mixed source at close distance was performed with the source at distances of approximately 0.625 in and 1.125 in from the detector. The differences in the resolution for the 4 single energy alpha peaks of the mixed source are found in Table 3. It appears that the resolution is fairly constant compared with the distance from the detector.

The main goal for using the ${ }^{252} \mathrm{Cf}$ source was to examine the fission spectrum in the high gain branch of the CPA16. A spectrum was taken in the low gain branch to examine the ${ }^{252} \mathrm{Cf}$ alpha peak. The resulting spectrum is seen in Fig. 7.

The ${ }^{252} \mathrm{Cf}$ alpha peak in Fig. 5 contains 3308 counts and 105 fissions were detected. The SF branching ratio is calculated from the data to be $3.08 \%$, which is extremely close to the literature value of 3.09\%. The fission peaks appear to be uneven as the higher fission peak falls right on the verge of saturating the preamp/amp. This behavior is not completely unexpected as the highest energy fission fragments had detector signals that were well above the $+5 \mathrm{~V}$ threshold that the CPA16 could handle. For a better understanding of the true shape of the fission peak, a longer count was taken in the high gain branch of the CPA16. The resulting fission spectrum can be seen in Fig. 8.

Using known values for the energies of the 2 fission peaks (78.3 MeV \& $103.5 \mathrm{MeV}$ ), the slope and intercept for the high gain branch were obtained (550.541 keV/channel and $11950.778 \mathrm{keV})$. With approximately 1800 channels available in the high gain channel of the CPA16, fissions up to $1000 \mathrm{MeV}$ should be detected, which should be sufficient for the expected use of the CPA16. The resolution of the fission peaks was $13.9 \mathrm{MeV}$ and $11.3 \mathrm{MeV}$ respectively.

\section{SUMMARY}

A detailed examination of the performance of the CPA16 preamplifier/amplifier module from multichannel* systems was performed. Both low and high gain channels work well, with the gain in the low branch of approximately $25 \mathrm{keV} / \mathrm{channel}$ and in the high branch of approximately $550 \mathrm{keV} / \mathrm{channel}$. Each branch has room for approximately 1800 channels making the detection of alpha and SF decay of interest extremely likely. The resolution for alpha decay was between $90-100 \mathrm{keV}$ for distances of 0.125 
in to 1.125 in from the PIPS detector. The resolution for the high gain fission channels was between 10$15 \mathrm{MeV}$. No evidence of cross-talk was discovered between the 16 channels of the CPA16 using both a pulser input signal or an input signal from the detector.

\section{ACKNOWLEDGEMENTS}

This work was performed under the auspices of the U.S. Department of Energy by Lawrence Livermore National Laboratory under contract No. W-7405-Eng-48.

[1] Yu. Ts. Oganessian, V. A. Shchepunov, S. N. Dmitriev, M. G. Itkis, G. G. Gulbekyan, M. V. Khabarov, V. V. Bekhterev, S. L. Bogomolov, A. A. Efremov, S. V. Pashenko, S. V. Stepantsov, A. V. Yeremin, M. I. Yavor, and A. G. Kalimov, Nucl. Instru. Methods Phys. Res. B 204, 606 (2003).

[2] Yu. Ts. Oganessian, V. K. Utyonkov, Yu. V. Lobanov, F. Sh. Abdullin, A. N. Polyakov, I. V. Shirokovsky, Yu. S. Tsyganov, G .G. Gulbekian, S. L. Bogomolov, B. N. Gikal, A. N. Mezentsev, S. Iliev, V. G. Subbotin, A. M. Sukhov, G. V. Buklanov, K. Subotic, M. G. Itkis, O. V. Ivanov, K. J. Moody, J. F. Wild, N. J. Stoyer, M. A. Stoyer, and R. W. Lougheed, Phys. Rev. C 62, 041604R (2000).

[3] Yu. Ts. Oganessian, V. K. Utyonkov, Yu. V. Lobanov, F. Sh. Abdullin, A. N. Polyakov, I. V. Shirokovsky, Yu. S. Tsyganov, G .G. Gulbekian, S. L. Bogomolov, B. N. Gikal, A. N. Mezentsev, S. Iliev, V. G. Subbotin, A. M. Sukhov, G. V. Buklanov, K. Subotic, M. G. Itkis, O. V. Ivanov, Y. E. Karelin, A. N. Tatarinov, K. J. Moody, J. F. Wild, N. J. Stoyer, M. A. Stoyer, C. A. Laue, and R. W. Lougheed, Phys. Rev. C 63, 011301R (2000).

[4] Yu. Ts. Oganessian, V. K. Utyonkov, Yu. V. Lobanov, F. Sh. Abdullin, A. N. Polyakov, I. V. Shirokovsky, Yu. S. Tsyganov, A. N. Mezentsev, S. Iliev, V. G. Subbotin, A. M. Sukhov, O. V. Ivanov, A. A. Voinov, K. Subotic, V. I. Zagrebaev, M. G. Itkis, K. J. Moody, J. F. Wild, M. A. Stoyer, N. J. Stoyer, C. A. Laue, D. A. Shaughnessy, J. B. Patin, and R. W. Lougheed, FLNR Internal Report, D7-2002-287 (2002). 
[5] Yu. Ts. Oganessian, V. K. Utyonkov, Yu. V. Lobanov, F. Sh. Abdullin, A. N. Polyakov, I. V. Shirokovsky, Yu. S. Tsyganov, G. G. Gulbekian, S. L. Bogomolov, A. N. Mezentsev, S. Iliev, V. G. Subbotin, A. M. Sukhov, A. A. Voinov, G. V. Buklanov, K. Subotic, V. I. Zagrebaev, M. G. Itkis, J. B. Patin, K. J. Moody, J. F. Wild, M. A. Stoyer, N. J. Stoyer, D. A. Shaughnessy, J. M. Kenneally, and R. W. Lougheed, Phys. Rev. C, submitted for publication (2003).

[6] Yu. Ts. Oganessian, V. K. Utyonkov, Yu. V. Lobanov, F. Sh. Abdullin, A. N. Polyakov, I. V. Shirokovsky, Yu. S. Tsyganov, G. G. Gulbekian, S. L. Bogomolov, B. N. Gikal, A. N. Mezentsev, S. Iliev, V. G. Subbotin, A. M. Sukhov, A. A. Voinov, G. V. Buklanov, K. Subotic, V. I. Zagrebaev, M. G. Itkis, J. B. Patin, K. J. Moody, J. F. Wild, M. A. Stoyer, N. J. Stoyer, D. A. Shaughnessy, J. M. Kenneally, and R. W. Lougheed, Phys. Rev. C, submitted for publication (2003).

[7] S. Y. F. Chu, L. P. Ekström, and R. B. Firestone, WWW Table of Radioactive Isotopes, http://nucleardata.nuclear.lu.se/nucleardata/toi/ (1999). 


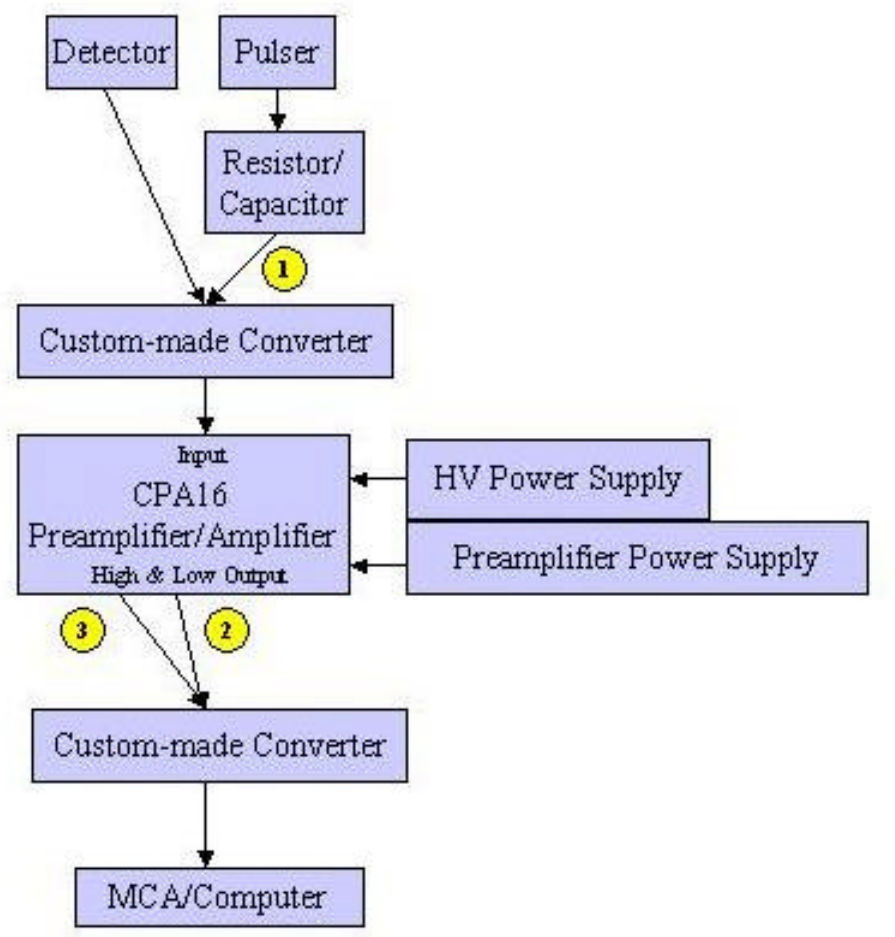

FIG. 1. A diagram of the electronics setup for the evaluation of the CPA16. Numbers 1, 2, and 3 show points in the electronics where signals were examined with an oscilloscope.

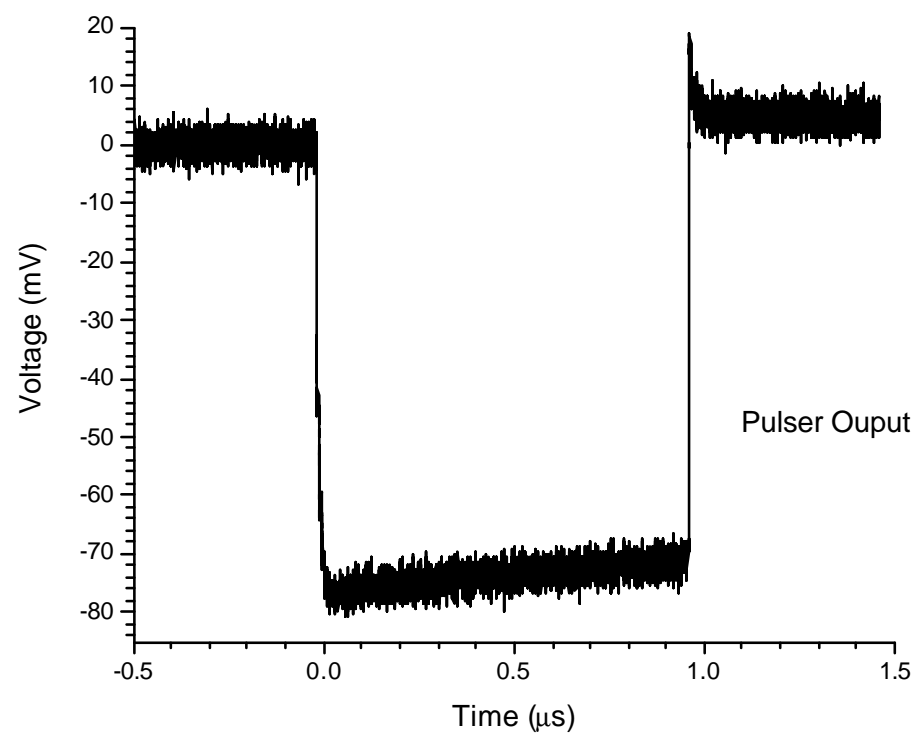

FIG. 2. The oscilloscope trace of the pulser output used as the input into the CPA16. The depth of the peak is $-70 \mathrm{mV}$ and the width is $1.0 \mu \mathrm{s}$. 


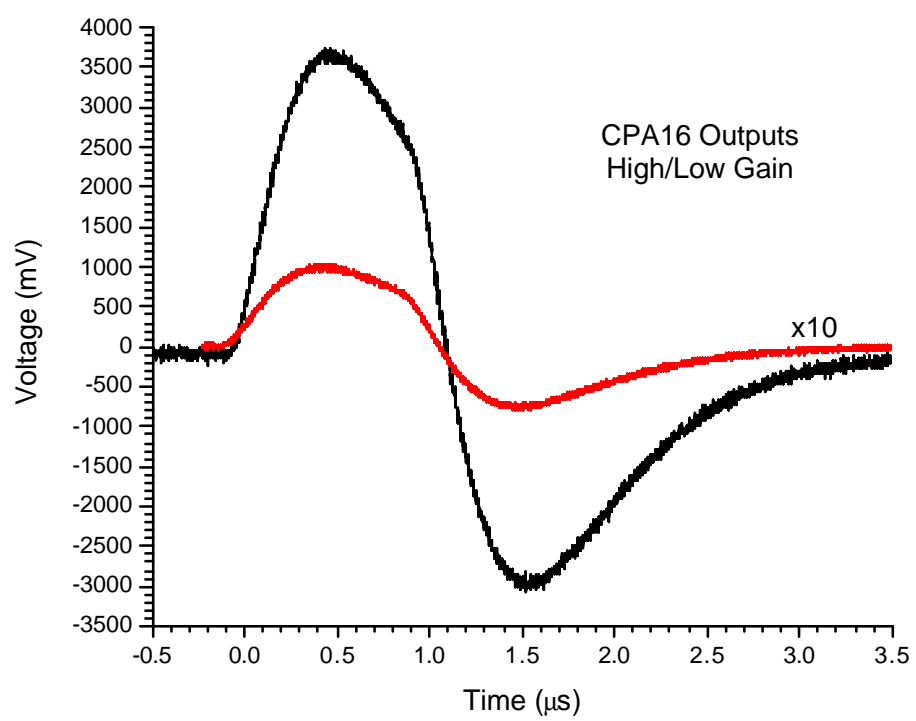

FIG. 3. The oscilloscope trace of the pulser signal as it exits the CPA16. The higher line is the result of the low gain channel (Number 2), and has a maximum signal of $+3.72 \mathrm{~V}$. The lower line has been multiplied by a factor of 10 and is the result of the high gain channel (Number 3 ). It has a maximum signal of +100 $\mathrm{mV}$.

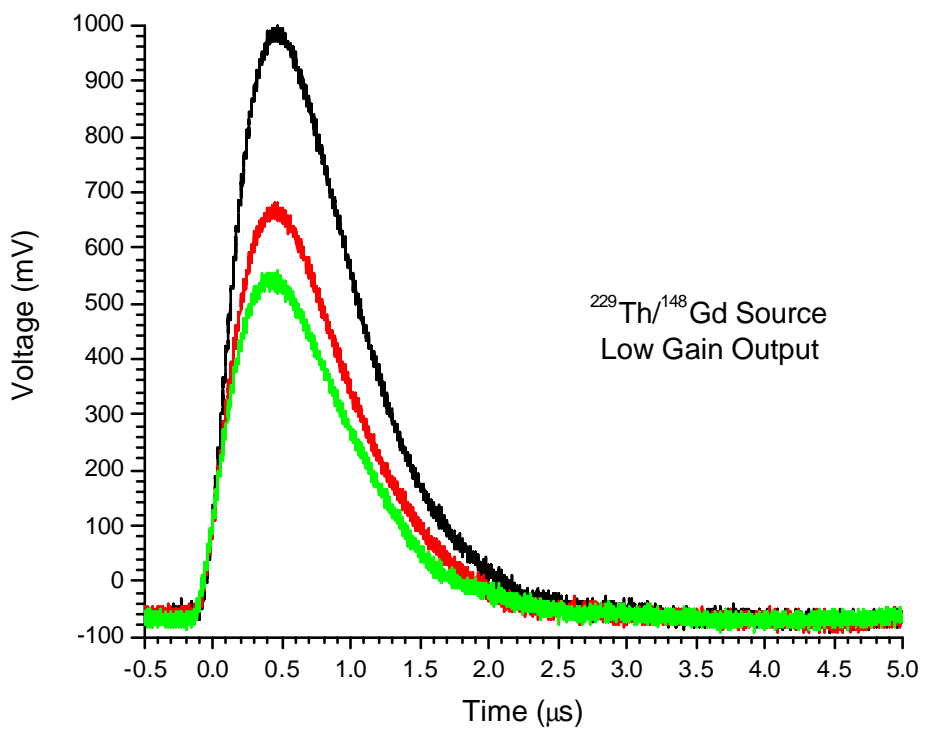

FIG. 4. The low gain output signal oscilloscope trace (Number 2). The three different signals represent three of the seven different alpha signals present. The oscilloscope trace from the high gain branch resembled the low gain branch oscilloscope trace with fission signals having peak heights between $400-$ $600 \mathrm{mV}$. 


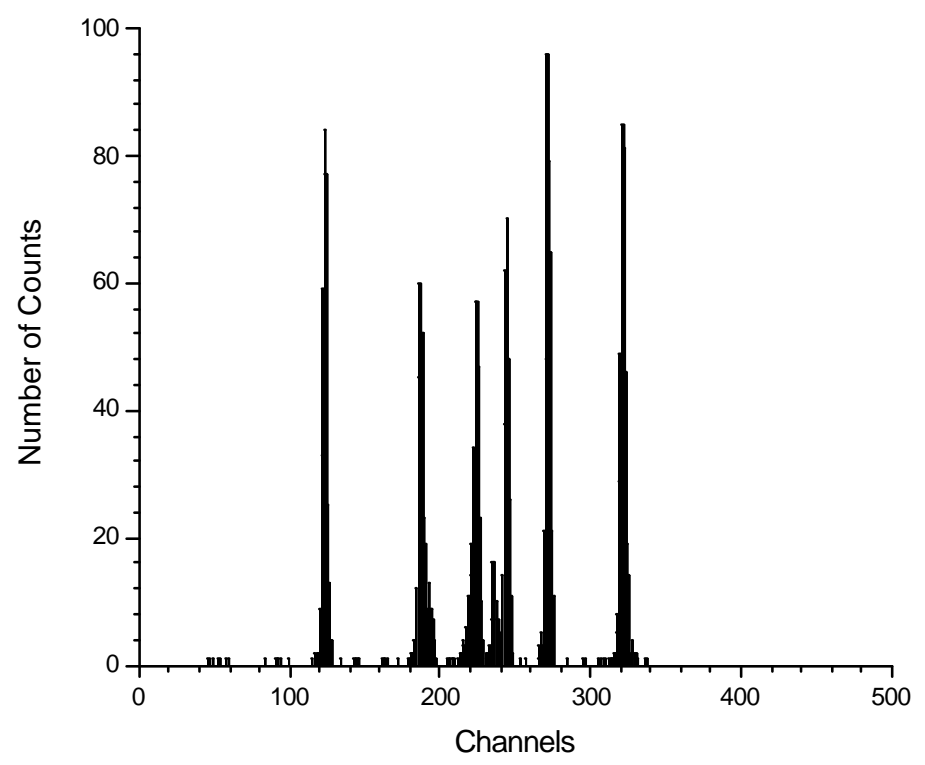

FIG. 5. Mixed source $\left({ }^{229} \mathrm{Th} \&{ }^{148} \mathrm{Gd}\right)$ spectrum taken over 10 minutes.

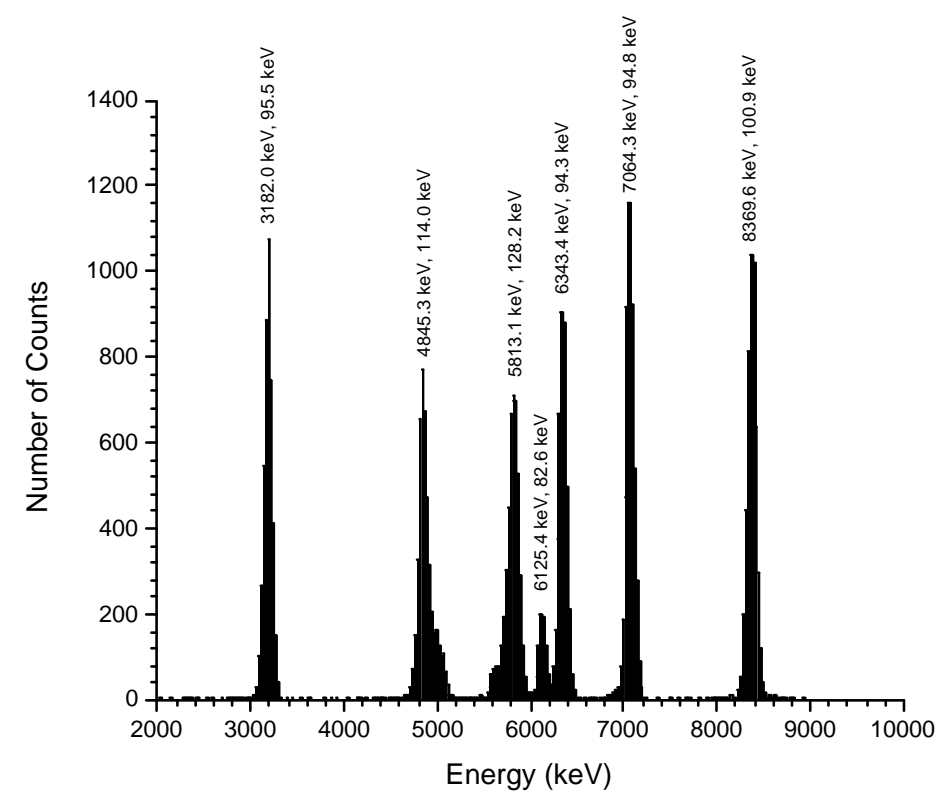

FIG. 6. Summed spectrum from 14 of the 16-preamp/amp channels using a mixed source $\left({ }^{229} \mathrm{Th} \&{ }^{148} \mathrm{Gd}\right)$. The Gaussian centroid energy $(\mathrm{keV})$ and FWHM (keV) are noted for each peak. 


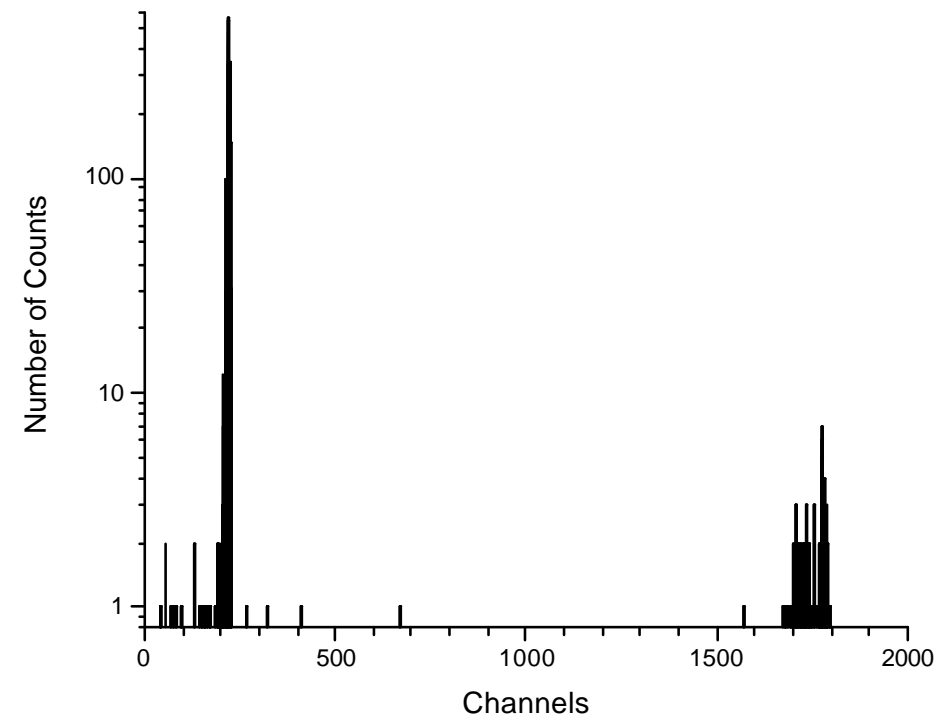

FIG. 7. ${ }^{252} \mathrm{Cf}$ spectrum from the low gain branch of the CPA16.

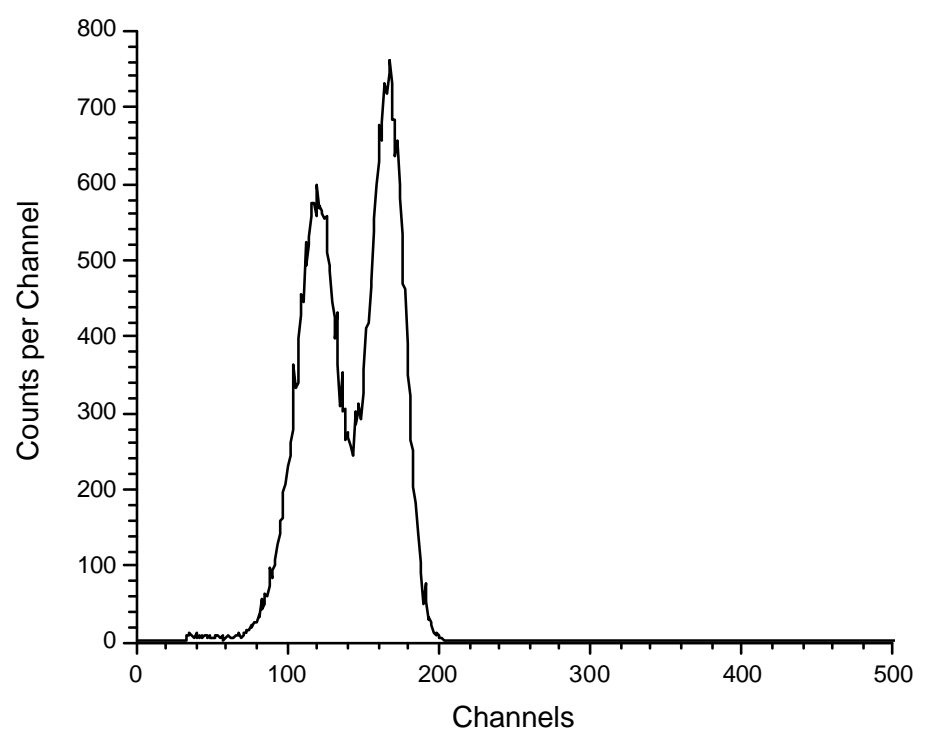

FIG. $8 .{ }^{252} \mathrm{Cf}$ spectrum from the high gain branch of the CPA16. 
TABLE 1. Mixed alpha-source list of isotope, alpha decay energy [7] and corrected alpha decay energies $\left(10 \mu \mathrm{g} / \mathrm{cm}^{2}\right.$ of gold). The ${ }^{229} \mathrm{Th}$ and ${ }^{225} \mathrm{Ac}$ decay energies were averaged based on the intensity of the three main alpha decay lines of each isotope.

\begin{tabular}{ccc} 
Isotope & $\mathrm{E}_{\alpha}(\mathrm{keV})$ & Corr. $\mathrm{E}_{\alpha}(\mathrm{keV})$ \\
\hline${ }^{148} \mathrm{Gd}$ & 3182.2 & 3180.0 \\
${ }^{229} \mathrm{Th}$ & 4849.0 & 4846.6 \\
${ }^{225} \mathrm{Ac}$ & 5816.9 & 5814.7 \\
${ }^{221} \mathrm{Fr}$ & 6126.3 & 6124.2 \\
${ }^{221} \mathrm{Fr}$ & 6341.0 & 6338.9 \\
${ }^{217} \mathrm{At}$ & 7066.9 & 7064.9 \\
${ }^{213} \mathrm{Po}$ & 8375.9 & 8374.1
\end{tabular}

TABLE 2. Slopes, intercepts, and FWHM (keV) for 14 of the 16 preamp/amp channels.

\begin{tabular}{|c|c|c|c|c|c|c|c|}
\hline Channel & 1 & 3 & 4 & 5 & 6 & 7 & 8 \\
\hline Slope & 24.70994 & 26.02367 & 24.80855 & 26.21597 & 26.18404 & 26.71120 & 26.03755 \\
\hline Intercept & 343.826 & 468.063 & 490.621 & 521.860 & -43.554 & -129.545 & 9.529 \\
\hline${ }^{148} \mathrm{Gd}$ & 104.7 & 98.0 & 93.5 & 101.9 & 86.3 & 100.6 & 95.0 \\
\hline${ }^{2{ }^{29} \mathrm{Th}}$ & 107.6 & 91.9 & 143.1 & 114.2 & 114.1 & 147.8 & 110.4 \\
\hline${ }^{225} \mathrm{Ac}$ & 104.7 & 64.3 & 119.8 & 101.9 & 95.6 & 116.4 & 76.6 \\
\hline${ }^{221} \mathrm{Fr}$ & 66.9 & 42.9 & 78.9 & 114.2 & 70.9 & 106.9 & 46.0 \\
\hline${ }^{221} \mathrm{Fr}$ & 90.2 & 95.0 & 96.4 & 98.8 & 95.6 & 94.4 & 101.2 \\
\hline${ }^{217} \mathrm{At}$ & 128.0 & 95.0 & 90.6 & 98.8 & 92.5 & 91.2 & 95.0 \\
\hline${ }^{213} \mathrm{Po}$ & 98.9 & 98.0 & 105.2 & 114.2 & 95.6 & 103.8 & 101.2 \\
\hline & & & & & & & \\
\hline $\mathrm{Channel}$ & 9 & 10 & 11 & 12 & 13 & 15 & 16 \\
\hline $\mathrm{Slope}$ & 26.11708 & 28.34883 & 25.01394 & 25.28586 & 26.46829 & 26.52281 & 26.11042 \\
\hline Intercept & 612.112 & -273.714 & 567.589 & 64.074 & 293.104 & -93.198 & 272.752 \\
\hline${ }^{148} \mathrm{Gd}$ & 101.5 & 106.8 & 94.2 & 83.4 & 84.1 & 90.6 & 83.0 \\
\hline${ }^{2{ }^{29} \mathrm{Th}}$ & 135.3 & 126.8 & 144.3 & 113.1 & 118.4 & 115.5 & 119.9 \\
\hline${ }^{225} \mathrm{Ac}$ & 101.5 & 133.5 & 111.9 & 142.9 & 115.3 & 124.9 & 126.0 \\
\hline${ }^{221} \mathrm{Fr}$ & 43.1 & 50.1 & 262.1 & 38.7 & 46.7 & 87.4 & 79.9 \\
\hline${ }^{221} \mathrm{Fr}$ & 107.6 & 103.5 & 91.3 & 98.2 & 77.9 & 96.8 & 89.2 \\
\hline${ }^{211} \mathrm{At}$ & 101.5 & 96.8 & 91.3 & 89.3 & 102.8 & 90.6 & 98.4 \\
\hline${ }^{213} \mathrm{Po}$ & 101.5 & 100.1 & 103.1 & 101.2 & 102.8 & 99.9 & 95.3 \\
\hline
\end{tabular}


TABLE 3. Resolutions of four peaks in the mixed source spectrum compared with distance from the detector.

\section{Resolution (keV)}

\begin{tabular}{cccc} 
Isotope & 0.125 in & 0.625 in & 1.125 in \\
\hline${ }^{148} \mathrm{Gd}$ & 95.5 & 87.5 & 93.4 \\
${ }^{221} \mathrm{Fr}$ & 94.3 & 110.2 & 93.9 \\
${ }^{217} \mathrm{At}$ & 94.8 & 107.8 & 98.1 \\
${ }^{213} \mathrm{Po}$ & 100.9 & 116.6 & 102.8
\end{tabular}

